\title{
The recA gene from Clostridium perfringens is induced by methyl methanesulphonate and contains an upstream Cheo box
}

\author{
Joanne L. Johnston, Joan Sloan, Janet A. M. Fyfe, John K. Davies \\ and Julian I. Rood
}

Author for correspondence: Julian I. Rood. Tel: +6139905 4825. Fax: +61399054811.

e-mail: julian.rood@med.monash.edu.au

Department of

Microbiology, Monash

University, Clayton,

Victoria 3168, Australia
The recA gene from Clostridium perfringens was cloned using degenerate oligonucleotide primers designed from conserved regions of RecA proteins from other bacteria. The 1089 bp gene encoded a putative RecA protein with $69 \%$ amino acid sequence similarity to the RecA protein from Bacillus subtilis. The $C$. perfringens recA gene was induced by exposure to methyl methanesulphonate and complemented a recA mutant of Escherichia coli. A Cheo box was identified in the region upstream of the gene. Since this SOS-like operator site is conserved in many DNA-damage-inducible recA gene regions from Gram-positive bacteria, the results suggest that the regulation of the $C$. perfringens recA gene also involves the binding of a LexA-like protein to this site.

Keywords: RecA, SOS operator site, DNA damage, Bacillus subtilis, regulation, Cheo box

\section{INTRODUCTION}

Clostridium perfringens is an anaerobic, Gram-positive bacterium which causes human gas gangrene and food poisoning and several animal diseases. $C$. perfringens strains produce a large number of extracellular toxins which play an important role in disease (Rood \& Cole, 1991; Songer, 1996). The genetics of C. perfringens is well developed but little is known about the recombination mechanisms or DNA repair systems that operate in this organism (Rood \& Cole, 1991; Cole et al., 1995).

In most prokaryotes the $\operatorname{rec} A$ gene encodes the major protein involved in homologous recombination, DNA repair, and the SOS response (Walker, 1984; Roca \& Cox, 1990). RecA proteins may also be involved in other processes such as the expression of extracellular proteins (Ball et al., 1990; McEnvoy et al., 1992), and heat shock and oxidative stress (Duwat et al., 1995). Although recA genes have been cloned from many different bacteria, only a relatively small number of Gram-positive

Abbreviation: MMS, methyl methanesulphonate.

The GenBank accession number for the nucleotide sequence data reported in this paper is U61497. organisms are represented (Karlin et al., 1995), and to our knowledge, no clostridial $\operatorname{rec} A$ genes have been cloned.

This study describes the cloning, sequence analysis, and characterization of the $C$. perfringens recA gene. The gene is shown to be induced upon treatment with methyl methanesulphonate (MMS) and to complement an Escherichia coli recA mutant. Comparative sequence analysis suggests that it is regulated by a similar mechanism to the recA gene from Bacillus subtilis.

\section{METHODS}

Bacterial strains and plasmids. All E. coli strains were derivatives of $\mathrm{DH} 5 \alpha$ (Bethesda Research Laboratories), which carries the recA1 mutation. Cultures were grown at $37^{\circ} \mathrm{C}$ in 2YT medium (Vieira \& Messing, 1982) with ampicillin $\left(100 \mu \mathrm{g} \mathrm{ml}^{-1}\right)$ or erythromycin $\left(150 \mu \mathrm{g} \mathrm{ml}^{-1}\right)$. C. perfringens strain 13 (Mahony \& Moore, 1976) was grown at $37^{\circ} \mathrm{C}$ under anaerobic conditions on nutrient agar ( $\operatorname{Rood}, 1983$ ) in an atmosphere containing $10 \% \mathrm{H}_{2}, 10 \% \mathrm{CO}_{2}$ and $80 \% \mathrm{~N}_{2}$, or in fluid thioglycollate broth (Difco) or TPG broth (Rood et al., 1978). The properties of the recombinant plasmids used in this study are described in Table 1.

DNA techniques. C. perfringens chromosomal DNA was prepared by the method of Abraham \& Rood (1985). DNA 
Table 1. Recombinant plasmids used in this study

\begin{tabular}{|c|c|c|}
\hline Plasmid & Characteristics & Reference \\
\hline pUC18 & $\mathrm{Ap}^{\mathrm{R}} l a c Z^{\prime}$ & Norrander et al. (1983) \\
\hline pWSK29 & $\mathrm{Ap}^{\mathrm{R}} \operatorname{lac} Z^{\prime}$ & Wang \& Kusher (1991) \\
\hline $\operatorname{pBSKS}(-)$ & $\mathrm{Ap}^{\mathrm{R}} l a c Z^{\prime}$ & Stratagene \\
\hline pJIR774 & pUC18 $\Omega\left(E c o \mathrm{RI} /\right.$ Bam HI : C. perfringens strain 13 PCR product \#414-\#415, 0.7 kb) Ap ${ }^{\mathrm{R}}$ & This study \\
\hline pJIR 828 & pWSK29 $\Omega\left(\right.$ EcoRI: C. perfringens strain $13,5 \cdot 2,3 \cdot 3,2 \cdot 7,1 \cdot 4$ kb fragments) Ap ${ }^{\mathrm{R}}$ & This study \\
\hline pJIR1120 & pBSKS $(-) \Omega(e r m Q$ cassette, $1 \cdot 3 \mathrm{~kb}) \mathrm{Ap}^{\mathrm{R}} \mathrm{Em}^{\mathrm{R}}$ & This study \\
\hline pJIR1197 & pWSK29 $\Omega($ EcoRI: pJIR $828,5 \cdot 2 \mathrm{~kb}) \mathrm{Ap}^{\mathrm{R}}$ & This study \\
\hline pJIR 1232 & pJIR1197 SphI $\Omega\left(S m a I / E c o R V:\right.$ pJIR1120, 1.3 kb) Ap ${ }^{\mathrm{R}} \mathrm{Em}^{\mathrm{R}}$ & This study \\
\hline
\end{tabular}

sequencing was performed with an Applied Biosystems 373A automated DNA sequencer using PRISM Ready Reaction DyeDeoxy Terminator Cycle Sequencing kits (Applied Biosystems). E. coli plasmid DNA was prepared using the Applied Biosystems protocol. Oligonucleotide primers were made using an Applied Biosystems 392 DNA/RNA synthesizer. The nucleotide sequence was compiled using Sequencher 3.0 (Gene Codes Corporation). Other molecular techniques were carried out by standard methods (Sambrook et al., 1989).

Isolation of the C. perfringens recA gene. A fragment of the $C$. perfringens recA gene was amplified using degenerate oligonucleotide primers designed from conserved regions of the RecA protein. The low mol $\% \mathrm{G}+\mathrm{C}$ content of $C$. perfringens DNA was taken into account in the design of the primers. BamHI and EcoRI restriction sites were engineered into the primers \#414 and \#415, respectively, to facilitate cloning of the PCR product. Primer \#414 [TTTGG(A/T)AAAGGATCCAT(A/T)ATGA] corresponded to the E. coli RecA peptide FGKGSIM and primer \#415 [CCATAGAT(A/T)ATATCGAATTC(A/T)GCTTG] corresponded to amino acids QAEFQILYG. PCR reactions were performed on a Hybaid Intelligent Heating Block, for 30 cycles using the following parameters: 1 min denaturation at $94^{\circ} \mathrm{C}, 2$ min annealing at $48^{\circ} \mathrm{C}$ and 2 min extension at $72{ }^{\circ} \mathrm{C}$.

A C. perfringens gene bank was constructed in the low-copynumber vector pWSK29 from an EcoRI digest of $C$. perfringens strain 13 chromosomal DNA. The library was screened by colony hybridization using the recA-derived PCR product labelled with digoxigenin (Boehringer Mannheim) as a probe.

RNA extraction and primer extension analysis. RNA was extracted by a modification of the method of Oelmuler et al. (1990) from C. perfringens cells grown to mid-exponential phase in either the presence or absence of $0 \cdot 1 \%$ MMS. Primer extension reactions were performed on $50 \mu \mathrm{g} C$. perfringens total RNA using the Primer Extension System and protocol outlined by Promega.

Sensitivity to MMS and UV light. E. coli strains were tested for sensitivity to MMS or UV light over a range of doses. Viable counts of serially diluted stationary-phase cultures were determined following UV irradiation under a germicidal lamp (Fyfe \& Davies, 1990). Sensitivity to MMS was determined by plating onto medium containing $0-0.02 \%$ MMS. Note that $E$. coli is more susceptible than $C$. perfringens to inhibition by MMS.

\section{RESULTS AND DISCUSSION}

\section{Cloning and complementation analysis of the recA gene from C. perfringens}

PCR using degenerate oligonucleotide primers has been used successfully to amplify and clone $r e c A$ genes from a number of Gram-positive bacteria and mycoplasmas (Quivey et al., 1992; Nußbaumer \& Wohlleben, 1994; Duwat et al., 1992; Dybvig et al., 1992; King et al., 1994; Tao et al., 1995). Therefore, a similar approach was used to clone the $C$. perfringens gene. The degenerate

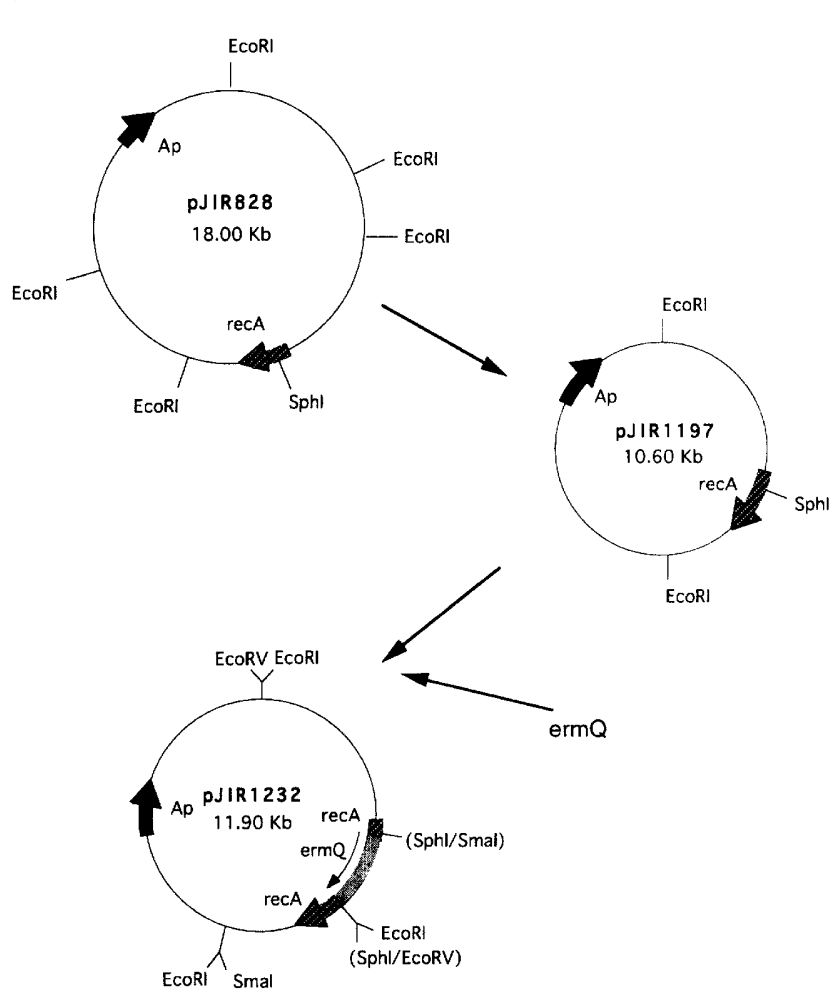

Fig. 1. Construction of an inactivated copy of recA in pJIR1232. The recA gene is indicated by the striped arrow. The extent and orientation of the ermQ gene within recA is shown by the shaded region. The $A p^{R}$ gene is indicated by a black arrow. Only relevant restriction sites are shown. 
oligonucleotide primers \#414 and \#415 were designed from conserved regions of the RecA protein. A $711 \mathrm{bp}$ DNA fragment was PCR-amplified from the $C$. perfringens strain 13 chromosome using these primers and cloned into pUC18 to form pJIR774. Nucleotide sequence analysis of the insert from pJIR774 and comparison with the GenBank database revealed that it encoded a putative product with a high level of amino acid sequence identity to RecA proteins from other bacterial species, which indicated that the PCR product contained a portion of the $C$. perfringens recA gene.

To isolate the entire recA gene from $C$. perfringens, a genomic library was constructed from EcoRI-digested C. perfringens strain 13 chromosomal DNA. The lowcopy-number vector $\mathrm{pWSK29}$ was used because the recA genes of some species appear to be unstable on highcopy-number plasmids (Fyfe \& Davies, 1990; Dybvig \& Woodard, 1992; Bayles et al., 1994; Marrero \& Yasbin, 1988). The $711 \mathrm{bp}$ PCR fragment was digoxigeninlabelled and used to probe the C. perfringens gene bank. A recombinant clone was detected which hybridized to the recA probe and produced a PCR product of the expected size on amplification with \#414 and \#415. Restriction analysis of the resultant plasmid, pJIR828, revealed the presence of four cloned EcoRI fragments. Southern hybridization experiments localized the $C$. perfringens recA gene to the $5.2 \mathrm{~kb}$ EcoRI fragment within pJIR828 (data not shown). This fragment was subsequently subcloned into pWSK29 to yield pJIR1197 (Fig. 1).

\section{The $C$. perfringens recA gene complements the $E$. coli recA1 mutation}

To determine if the $C$. perfringens recA gene could complement a recA strain of $E$. coli, viable counts were performed following exposure of cells to UV irradiation or after growth in the presence of different concentrations of MMS. The strains used were $\mathrm{DH} 5 \alpha$ derivatives carrying pJIR828 or pJIR1197, which had a complete copy of the C. perfringens recA gene, or pJIR1232, which carried an insertionally inactivated recA gene (Table 1). The inactivated recA gene was constructed by insertion of the erythromycin resistance (ermQ) cassette from pJIR1120 into the SphI site of pJIR1197 (Fig. 1). E. coli DH5 $\alpha$ strains carrying either pJIR828 or pJIR1197 showed increased resistance to MMS (Fig. 2a) and increased survival following UV irradiation (Fig. 2b) when compared with the vector control or the recA::erm $Q$ derivative. These results show that the C. perfringens recA gene is functional in $E$. coli and suggest that the clostridial RecA protein can substitute for the E. coli RecA protein in conferring resistance to MMS and survival following UV irradiation.

\section{Sequence analysis of the $C$. perfringens recA gene and its upstream region}

Outward-firing oligonucleotide primers for sequencing of the upstream and downstream regions were designed
Table 2. Comparison of putative Cheo boxes from the recA genes of several Gram-positive bacteria

\begin{tabular}{|ll|}
\hline Organism & Putative Cheo box \\
\hline Clostridium perfringens & GAACTTATGTTC \\
Bacillus subtilis & GAATATGCGTTC \\
Staphylococcus aureus & GAACAAATATTC \\
Streptococcus pneumoniae & GAACTGAGGTTA \\
Mycobacterium tuberculosis & GAACAGGTGTTC \\
Mycobacterium leprae & GAACAGATGTTC \\
Streptomyces lividans & GAACATCCATTC \\
Streptomyces ambofaciens & GAACATCCATTC \\
Lactococcus lactis & GAAAAAT-GTTC \\
& GATAGAAAGTTC \\
Corynebacterium glutamicum & GTGACAAAGTTC \\
Consensus & GAATTTTCGTCC \\
\hline
\end{tabular}

from known sequences within the $711 \mathrm{bp}$ recA fragment. The entire recA gene then was sequenced on both strands in an overlapping manner using pJIR1197 and pJIR828 as the templates. The recA gene encoded a putative 362 amino acid protein that had $69 \%$ identity to the product of the $B$. subtilis recA gene, with the most highly conserved residues being located in the $\mathrm{N}$ terminal region. The $C$. perfringens gene was most closely related to recA genes from B. subtilis, Staphylococcus aureus, Mycobacterium tuberculosis and $\mathrm{Myco-}$ bacterium leprae (Karlin et al., 1995). For a complete comparative alignment of the RecA amino acid sequence see Roca \& Cox (1997). A 28 bp inverted repeat, which may act as a factor-independent transcriptional terminator, was found directly downstream of the end of the gene and an imperfect inverted repeat structure, which could have regulatory significance, was located upstream of the gene (Fig. 3). A putative $\sigma^{70}$ promoter sequence was identified upstream of the recA coding region.

In B. subtilis a conserved motif (GAAC- $\mathrm{N}_{4}$-GTTC), called a Cheo box, has been identified in the upstream regions of damage-inducible genes (Cheo et al., 1991). Deletion analysis of the B. subtilis recA promoter region has shown that this motif is required for the regulation of recA expression in B. subtilis (Cheo et al., 1992, 1993). This sequence has also been identified in the promoter regions of the recA genes from other Gram-positive bacteria such as M. tuberculosis, M. leprae, Staphylococcus aureus, Streptomyces lividans, Streptomyces ambofaciens and Streptococcus pneumoniae (Davis et al., 1991, 1994; Bayles et al., 1994; Nußbaumer \& Wohlleben, 1994; Pearce et al., 1995). Similar sequences also exist upstream of the recA genes from Lactococcus lactis and Corynebacterium glutamicum, although these sequences are less well conserved (Duwat et al., 1992). Analysis of the $C$. perfringens recA sequence revealed that there was a consensus Cheo box (Table 2) located 

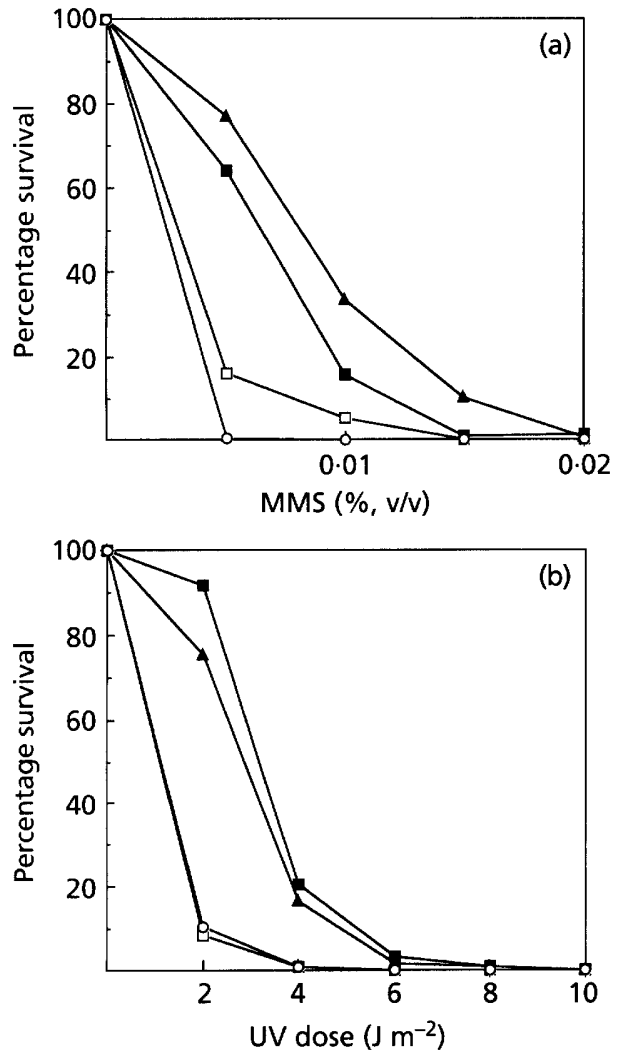

Fig. 2. Complementation of the $E$. coli recA1 mutation. Viable counts were carried out on DH5 $\alpha$ strains carrying pWSK29 ( $\square)$, pJIR828 (A), pJIR1197 ( $\mathbf{a}$ ) or pJIR1232 (O) following treatment of cell cultures with (a) MMS or (b) UV radiation. Values represent the means of two independent experiments.

$8 \mathrm{bp}$ downstream of the putative -10 promoter sequence (Fig. 3).

In Escherichia coli, the SOS regulon is controlled by both LexA and RecA. LexA acts as a repressor of SOS genes by binding to a consensus sequence, the SOS box, in the upstream region of these genes. Induction is achieved as a result of DNA damage, by activation of the $E$. coli RecA protein, which then mediates autoproteolytic cleavage of the LexA repressor (Walker, 1984). Regulation of the SOS response in B. subtilis occurs via a similar mechanism. A LexA-like protein has been identified from $B$. subtilis and shown to bind specifically to the Cheo box or SOS operator site in the promoter regions of damage-inducible genes (Lovett $e t$ al., 1993). This binding is abolished by activated $B$. subtilis RecA protein. The nature of the inducing signal which results in activation appears to be conserved in both B. subtilis and E. coli (Lovett et al., 1994). The presence of similar operator sites in the upstream regions of the C. perfringens recA gene and $r e c A$ genes from other Gram-positive bacteria suggests that the mechanism of regulation of these genes has been conserved between these organisms.
1 AATAAAAATGTTATAAATACTTATAAATAATGTTTTAAAAGTCAAAAAATAGTCAATTAT

61 TAAGACATGAGGTTCTTTTAAGAACTTCATGTTGATGTTGACTTTTTTTTTGTATATATT

121 ATAATAATAGTAGSACTTATGHGGGTTATTTAAGGAGGTACGTATGGCAAATATAGAT $M$ A $N$ I D

181 AAAGATAAATTAAAAGCTATTGAGATGGCTATGGGTCAAATAGAGAAGCAATTTGGAAAG $\begin{array}{llllllllllllllllllll}K & D & K & L & K & A & I & E & M & A & M & G & Q & I & E & K & Q & F & G & K\end{array}$

Fig. 3. Nucleotide sequence of the region upstream of the recA gene. Consensus -10 and -35 promoter regions are shown in bold. The putative Cheo box is shown in outline. The putative RBS and the transcriptional start site are underlined. The imperfect inverted repeat is indicated by the arrows.

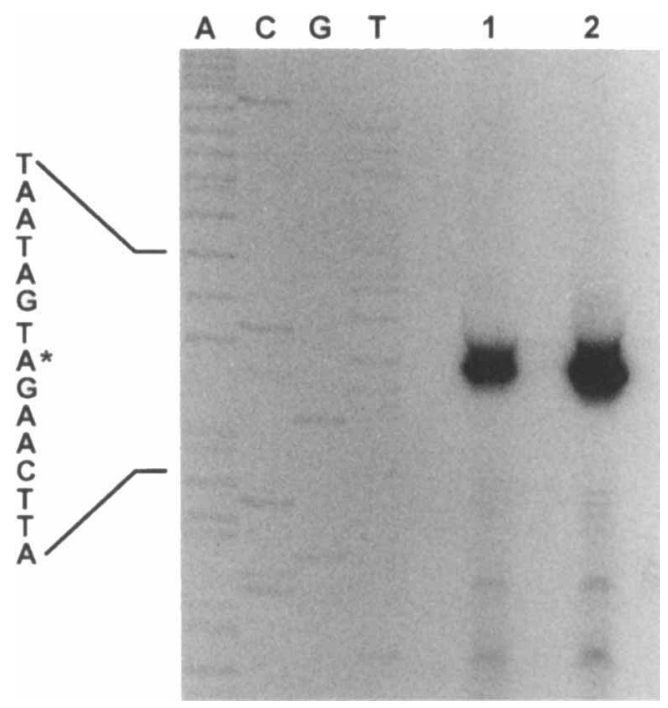

Fig. 4. Mapping of the $C$. perfringens recA transcript. Primer extension experiments were performed on $50 \mu \mathrm{g} \mathrm{C}$. perfringens RNA samples isolated from mid-exponential-phase cells grown in TPG broth (lane 1) or TPG broth with $0.1 \%$ MMS (lane 2). The sequence of the coding strand is shown. The transcriptional start point is indicated by the asterisk.

\section{Determination of the transcription start site of the recA gene}

To map the transcription start point of the $C$. perfringens recA gene, and to determine whether the recA transcript was induced following DNA damage, RNA was extracted from $C$. perfringens cells grown in the presence or absence of $0 \cdot 1 \%$ MMS. Primer extension experiments (Fig. 4) were used to map the beginning of the transcript to the A residue located immediately upstream of the Cheo box (Fig. 3). Transcription of recA appeared to be induced following growth of the $C$. perfringens cells in the presence of $0.1 \%$ MMS, suggesting that the recA gene is derepressed by DNA damage. To confirm this observation, dot-blots were carried out on RNA purified from cultures grown in the presence and absence of MMS. The results showed that 
the $\operatorname{rec} A$ gene, but not the control gyrA gene, was induced by exposure to MMS. It is likely that in C. perfringens there is a regulatory system similar to the SOS system of $B$. subtilis, whereby DNA damage results in activation of the RecA protein and leads to cleavage and inactivation of a LexA-like repressor protein which is normally bound at the SOS operator site. The net result would be induction of the $\operatorname{rec} A$ gene and other potential damage-inducible genes from $C$. perfringens.

In summary, this study has led to the cloning and genetic analysis of the recA gene from $C$. perfringens and provided evidence that it is induced upon response to DNA damage. The data suggest that this gene has a similar function in DNA repair to that of the E. coli recA gene and is regulated via a similar mechanism to the recA gene from $B$. subtilis.

\section{REFERENCES}

Abraham, L. J. \& Rood, J. I. (1985). Molecular analysis of transferable tetracycline resistance plasmids from Clostridium perfringens. J Bacteriol 161, 636-640.

Ball, T. K., Wasmuth, C. R., Braunagel, S. C. \& Benedik, M. J. (1990). Expression of Serratia marcescens extracellular proteins requires recA. J Bacteriol 171, 342-349.

Bayles, K. W., Brunskill, E. W., landolo, J. J., Hruska, L. L., Huang, S., Pattee, P. A., Smiley, B. K. \& Yasbin, R. E. (1994). A genetic and molecular characterization of the recA gene from Staphylococcus aureus. Gene 147, 13-20.

Cheo, D. L., Bayles, K. W. \& Yasbin, R. E. (1991). Cloning and characterization of DNA damage-inducible promoter regions from Bacillus subtilis. J Bacteriol 173, 1696-1703.

Cheo, D. L., Bayles, K. W. \& Yasbin, R. E. (1992). Molecular characterization of regulatory elements controlling expression of the Bacillus subtilis recA ${ }^{+}$gene. Biochimie 74, 755-762.

Cheo, D. L., Bayles, K. W. \& Yasbin, R. E. (1993). Elucidation of regulatory elements that control damage induction and competence induction of the Bacillus subtilis SOS system. J Bacteriol 175, 5907-5915.

Cole, S. T., Canard, B., Cornillot, E., Garnier, T., Guillouard, L., Saint-Joanis, B. \& Rood, J. I. (1995). Molecular genetics of Clostridium perfringens. In Medical and Dental Aspects of Anaerobes, pp 363-371. Edited by B. I. Duerden, W. G. Wade, J. S. Brazier, A. Eley, B. Wren \& M. J. Hudson. Northwood: Science Reviews.

Davis, E. O., Sedwick, S. G. \& Colston, M. J. (1991). Novel structure of the recA locus of Mycobacterium tuberculosis implies processing of the gene product. J Bacteriol 173, 5653-5662.

Davis, E. O., Thangaraj, H. S., Brooks, P. C. \& Colston, M. J. (1994). Evidence of selection for protein introns in the RecAs of pathogenic mycobacteria. EMBO 13, 699-703.

Duwat, P., Ehrlich, S. D. \& Gruss, A. (1992). Use of degenerate primers for polymerase chain reaction cloning and sequencing of the Lactococcus lactis subsp. lactis recA gene. Appl Environ Microbiol 58, 2674-2678.

Duwat, P., Ehrlich, S. D. \& Gruss, A. (1995). The recA gene of Lactococcus lactis: characterization and involvement in oxidative and thermal stress. Mol Microbiol 17, 1121-1131.

Dybvig, K. \& Woodard, A. (1992). Cloning and DNA sequence of a mycoplasmal recA gene. J Bacteriol 174, 778-784.

Dybvig, K., Hollingshead, S. K., Heath, D. G., Clewell, D. B., Sun,
F. \& Woodard, A. (1992). Degenerate oligonucleotide primers for enzymatic amplification of recA sequences from gram-positive bacteria and mycoplasmas. J Bacteriol 174, 2729-2732.

Fyfe, J. A. M. \& Davies, J. K. (1990). Nucleotide sequence and expression in Escherichia coli of the recA gene of Neisseria gonorrboeae. Gene 93, 151-156.

Karlin, S., Weinstock, G. M. \& Brendl, V. (1995). Bacterial classifications derived from RecA protein sequence comparisons. J Bacteriol 177, 6881-6893.

King, K, W., Woodard, A. \& Dybvig, K. (1994). Cloning and characterization of the recA genes from Mycoplasma pulmonis and M. mycoides subsp. mycoides. Gene 139, 111-115.

Lovett, C. M., Kerry, C. C. \& O'Gara, T. M. (1993). Purification of an SOS repressor from Bacillus subtilis. I Bacteriol 175, 6842-6849.

Lovett, C. M., O'Gara, T. M. \& Woodruff, J. N. (1994). Analysis of the SOS inducing signal in Bacillus subtilis using Escherichia coli LexA as a probe. J Bacteriol 176, 4914-4923.

McEnvoy, J. L., Murata, H. \& Chatterjee, A. K. (1992). Genetic evidence for an activator required for induction of pectin lyase in Erwinia caratovora subsp. carotovora by DNA-damaging agents. J Bacteriol 174, 5471-5474.

Mahony, D. E. \& Moore, T.I. (1976). Stable L-forms of Clostridium perfringens and their growth on glass surfaces. Can J Microbiol 22, 953-959.

Marrero, R. \& Yasbin, R. E. (1988). Cloning of the Bacillus subtilis $r e c E^{+}$gene and functional expression of $r e c E^{+}$in B. subtilis. J Bacteriol 170, 335-344.

Norrander, J., Kempe, T. \& Messing, J. (1983). Construction of improved M13 vectors using oligonucleotide-directed mutagenesis. Gene 26, 101-106.

Nußbaumer, B. \& Wohlleben, W. (1994). Identification, isolation and sequencing of the $r e c A$ gene of Streptomyces lividans TK24. FEMS Microbiol Lett 118, 57-64.

Oelmuler, U., Kruger, N., Steinbuchel, A. \& Friedrich, G. C. (1990). Isolation of prokaryotic RNA and detection of specific mRNA with biotinylated probes. J Microbiol Methods 11, 73-84.

Pearce, B. J., Naughton, A. M., Campbell, E. A. \& Masure, H. R. (1995). The rec locus, a competence-induced operon in Streptococcus pneumoniae. J Bacteriol 177, 86-93.

Quivey, R. G., Jr \& Fraustoferri, R. C. (1992). In vivo inactivation of the Streptococcus mutans recA gene mediated by PCR amplification and cloning of a recA DNA fragment. Gene 116, $34-42$.

Roca, A. I. \& Cox, M. M. (1990). The RecA protein, structure and function. Crit Rev Biochem Mol Biol 25, 415-456.

Roca, A. I. \& Cox, M. M. (1997). RecA protein: structure, function and role in recombinational DNA repair. Prog Nucleic Acid Res Mol Biol 56, 129-223.

Rood, J. I. (1983). Transferable tetracycline resistance in Clostridium perfringens strains of porcine origin. Can J Microbiol 29, 1241-1246.

Rood, J. I. \& Cole, S. T. (1991). Molecular genetics and pathogenesis of Clostridium perfringens. Microbiol Rev 55, 621-648.

Rood, J. I., Maher, E. A., Somers, E. B., Campos, E. \& Duncan, C. L. (1978). Isolation and characterization of muliply antibioticresistant Clostridium perfringens strains from porcine feces. Antimicrob Agents Chemother 13, 871-880.

Sambrook, J., Fritsch, E. F. \& Maniatis, T. (1989). Molecular Cloning: a Laboratory Manual. Cold Spring Harbor, NY: Cold Spring Harbor Laboratory. 
Songer, J. G. (1996). Clostridial enteric diseases of domestic animals. Clin Microbiol Rev 9, 216-234.

Tao, L., Hollingshead, S. K., Suvorov, A. N., Ferretti, J. J. \& McShan, W. M. (1995). Construction of a Streptococcus pyogenes $r e c A$ mutant via insertional inactivation, and cloning and sequencing of the complete recA gene. Gene 162, 59-62.

Vieira, J. \& Messing, J. (1982). The pUC plasmids, an M13mp7derived system for insertion mutagenesis and sequencing with synthetic universal primers. Gene 19, 259-268.
Walker, G. C. (1984). Mutagenesis and inducible responses to deoxyribonucleic acid damage in Escherichia coli. Microbiol Rev 48, 60-93.

Wang, R. F. \& Kushner, S. R. (1991). Construction of versatile lowcopy-number vectors for cloning, sequencing and gene expression in Escherichia coli. Gene 100, 195-199.

Received 1 July 1996; revised 27 October 1996; accepted 31 October 1996. 